\title{
Genetic variant in visfatin gene promoter contributes to reduced risk of hepatocellular carcinoma in a Chinese population
}

\author{
Zhitong $\mathbf{W u}^{1, *}$, Yifan Sun ${ }^{2, *}$, Yiyong Huang ${ }^{2}$, Shengbo Zhu ${ }^{2}$, Yi Feng ${ }^{1}$, Huifen $\mathrm{Ye}^{1}$, \\ Chunming Liu ${ }^{2}$, Shifu Tang ${ }^{2}$ \\ ${ }^{1}$ Department of Clinical Laboratory, Eighth Affiliated Hospital of Guangxi Medical University, Guigang City People's Hospital, \\ Guigang, Guangxi, China \\ ${ }^{2}$ Department of Clinical Laboratory, Third Affiliated Hospital of Guangxi University of Chinese Medicine, Liuzhou, Guangxi, \\ China \\ "These authors have contributed equally to the article, so they should be considered as the co-first authors
}

Correspondence to: Yifan Sun, email: sunyifan13@126.com

Keywords: visfatin, polymorphism, hepatocellular carcinoma

Received: September 07, $2016 \quad$ Accepted: October 12, $2016 \quad$ Published: October 25, 2016

\section{ABSTRACT}

Knowledge on the role of gene variants in the visfatin promoter region in the hepatitis B virus (HBV)-related liver diseases is limited. In this study, we genotyped two potentially functional single nucleotide polymorphisms (SNPs) in the visfatin promoter region, $-1535 \mathrm{C}>\mathrm{T}$ (rs61330082) and -3187G >A (rs11977021), in $120 \mathrm{HBV}-$ related chronic hepatitis B (CHB) patients, $140 \mathrm{HBV}$-related liver cirrhosis (HBVLC) patients, 243 HBV-related hepatocellular carcinoma (HBV-HCC) patients, and 224 asymptomatic HBV carriers. Odds ratios (ORs) with $95 \%$ confidence intervals (CIs) were calculated by logistic regression. The results showed subjects with a TT genotype of $-1535 \mathrm{C}>\mathrm{T}$ had a significantly decreased risk of $\mathrm{HBV}-\mathrm{HCC}$ related to the CC and CC + CT genotypes (adjusted OR $=0.493,95 \% \mathrm{CI}=0.313-0.778$; OR = $0.535,95 \% \mathrm{CI}=0.362-0.791$, respectively). A lowered risk also appeared in the comparison between allele $\mathrm{T}$ and allele C $(\mathrm{OR}=0.734,95 \%, \mathrm{CI}=\mathbf{0 . 5 8 1 - 0 . 9 5 0})$. However, these associations existed only in people with Zhuang ethnicity, but not in people with Han ethnicity. There were no significant associations between -3187G >A polymorphisms and the risk of HBV-related liver diseases. Our results suggested that visfatin $-1535 \mathrm{C}>\mathrm{T}$ polymorphisms might be associated with decreased risk of HBVHCC among the ethnic Zhuang population in Guangxi, China.

\section{INTRODUCTION}

Hepatocellular carcinoma (HCC) is a common type of liver cancer with high morbidity and mortality, and it is estimated that about 466,100 new cases happened in China, 2015, and about 422,100 Chinese died from HCC [1]. HCC is a multifactorial disease, with hepatitis $\mathrm{B}$ virus (HBV) and $\mathrm{C}(\mathrm{HCV})$ infections, aflatoxin-B1 (AFB1) exposure, and excessive alcohol intake considered to be the most prominent etiologies linked to the development of $\operatorname{HCC}[2,3]$. Over the last two decades, the rising incidence of HCC has been related to the burgeoning incidence of obesity, nonalcoholic fatty liver disease (NAFLD), and metabolic syndrome [4]. However, the accurate etiology of HCC remains elusive; for example, the mechanisms of genomic alterations in $\mathrm{HCC}$ require examination [5].
Frequently, HCC development is associated with the induction of inflammation [6,7]. Genetic mutations in inflammation-related genes, especially in cytokines, may be involved in the progression of HCC. Recent studies have suggested that mutations in cytokines, such as tumor necrosis factor- $\alpha(\mathrm{TNF}-\alpha)$, interferon gamma (IFN- $\gamma$ ), interleukin-18 (IL-18) [8], IL-6 [9], IL-4 [10], and IL-17 [11], were associated with the risk of HCC. Visfatin -also called nicotinamide phosphoribosyltransferase (NAMPT), pre-B-cell colony-enhancing factor (PBEF) - is a common adipocytokine released by the adipose tissue. Visfatin is upregulated during adipocyte differentiation and involved in the pathogenesis of NAFLD [12], regulates cell energy balance in chronic hepatitis [13]. Elevated visfatin expression has been reported in various digestive system cancers [14-16]. 
The visfatin gene, located on chromosome $7 q 22$, spans an approximate length of $34.7 \mathrm{kbp}$ and exhibits 11 exons and 10 introns [17]. Several frequent polymorphisms of the visfatin gene were reported to be associated with low-grade inflammation, type 2 diabetes, obesity, and coronary artery disease [18-20]. Of the single nucleotide polymorphisms (SNPs) in the visfatin promoter region, the $-1535 \mathrm{C}>\mathrm{T}$ (rs61330082) and $-3187 \mathrm{G}>\mathrm{A}$ (rs11977021) loci have been widely studied as disease contributors, because they regulate the expression of the visfatin gene $[21,22]$. In fact, recent genetic studies have revealed that polymorphisms of $-1535 \mathrm{C}>\mathrm{T}$ were associated with both increased bladder cancer risk [23] and esophageal squamous cell carcinoma risk [24]. Nevertheless, the potential role of visfatin gene polymorphisms in HCC development remains unknown, and no genome-wide association studies (GWASs) have addressed these SNPs in HCC patients. We hypothesized that the visfatin gene polymorphisms may be associated with risk of HCC, and carried out a case-control study to investigate the association between the $-1535 \mathrm{C}>\mathrm{T}$ and $-3187 \mathrm{G}>\mathrm{A}$ polymorphisms and $\mathrm{HCC}$ risk.

\section{RESULTS}

\section{Demographic characteristics}

The basic characteristics of the study population are shown in Table 1. Significant differences were found between the patients and controls in terms of gender, age, ethnicity, and drinking status $(P$-value $<0.05)$. The number of females was significantly lower among the HBV-HCC patients compared with the control group $(8.2 \%$ versus $44.2 \%, P<0.001)$. The CHB patients were, on average, 10 years younger than the HBV-LC, HBV-HCC patients, and the control group. No significant differences in BMI or smoking were identified across the study groups.

\section{Association of visfatin polymorphisms with the risk of $\mathrm{HBV}$-related liver diseases}

The genotype and allele frequencies of visfatin $-1535 \mathrm{C}>\mathrm{T}$ and $-3187 \mathrm{G}>\mathrm{A}$ polymorphisms between the patients and the control subjects are shown in Table 2. All loci did not display deviation from HWE in either the patient or the control groups $\left(\chi^{2}=0.365, P=0.546\right.$ for $-1535 \mathrm{C}>\mathrm{T} ; \chi^{2}=1.789, P=0.181$ for $-3187 \mathrm{G}>\mathrm{A}$ ), suggesting that the subjects used in our study were chosen randomly from the population.

Regarding visfatin $-1535 \mathrm{C}>\mathrm{T}$ polymorphism, TT, $\mathrm{CT}$, and $\mathrm{CC}$ genotypes were found in both the patients and control subjects (Figure 1A, 1B). Although the prevalence of the TT genotype was lower in the HBV-LC (11.4\%) and HBV-HCC $(10.7 \%)$ patients when compared with the control group $(15.2 \%)$, the distribution of the visfatin genotype and allele frequencies did not differ significantly between the patient and the control groups $(P>0.05)$. Results from logistic regressive analyses, adjusted for confounding factors, are shown in Table 2. Significant associations were observed between the visfatin $-1535 \mathrm{C}>\mathrm{T}$ polymorphism and $\mathrm{HBV}-\mathrm{HCC}$ risk in the co-dominant model (TT versus $\mathrm{CC}$ : OR $=0.493,95 \% \mathrm{CI}=0.313-0.778$, $P=0.002$ ), the recessive model (TT versus CT $+\mathrm{CC}: \mathrm{OR}$ $=0.535,95 \% \mathrm{CI}=0.362-0.791, P=0.002)$, and the allelic model (allele $\mathrm{T}$ versus allele $\mathrm{C}: \mathrm{OR}=0.734,95 \% \mathrm{CI}=$ 0.58-0.950, $P=0.018$ ).

In addition, significant associations between visfatin $-1535 \mathrm{C}>\mathrm{T}$ polymorphism and $\mathrm{HBV}-\mathrm{LC}$ risk were presented in a co-dominant model (TT versus CC: OR $=0.609,95 \% \mathrm{CI}=0.373-0.994, P=0.047)$. However, we did not observe significant associations between the visfatin- $1535 \mathrm{C}>\mathrm{T}$ polymorphisms and $\mathrm{CHB}$ risk under any comparison models (all $P>0.05$, Table 2 ). The analysis of intermediate traits was further performed using CHB and LC samples combined, and no significant associations were observed (all $P>0.05$, data not shown).

With visfatin $-3187 \mathrm{G}>\mathrm{A}$ polymorphism, three genotypes (TT, CT, and CC, as shown in Figure 1C, 1D) were successfully identified in both the patient and control groups. Genotype and allele analysis found no significant differences within the genotype distribution across the study groups $(P=0.345)$, or in the allele distribution $(P=0.217)$. Logistic regression analysis, adjusted for gender, age, ethnicity, and drinking status, showed that no single genotype or allele of visfatin $-3187 \mathrm{G}>\mathrm{A}$ loci was associated with an altered risk for CHB, HBV-LC, or HBV-HCC (all $P>0.05$; see Table 2).

Considering the significant differences of distribution for gender, age, ethnicity, and drinking status, genotype distributions of the two SNPs in different groups stratified by those patient characteristics were also analyzed. According to Table 1, gender was stratified between male and female groups; age was stratified by $<50$ and $\geq 50$ groups; ethnicity was stratified between Zhuang and Han groups; BMI was stratified as $<25 \mathrm{~kg}$ / $\mathrm{m}^{2}$ and $\geq 25 \mathrm{~kg} / \mathrm{m}^{2}$ groups; and the smoking and drinking statuses were stratified between the "Yes" and "No" groups. Interestingly, the association between visfatin $-1535 \mathrm{C}>\mathrm{T}$ polymorphisms and HBV-HCC risk was found in the Zhuang ethnicity population, but not in the Han ethnicity population (Table 3). Statistically, the visfatin $-1535 \mathrm{C}>\mathrm{T}$ TT genotype was associated with a decreased risk of $\mathrm{HCC}$ compared with the $\mathrm{CC} / \mathrm{CT}$ genotypes among the Zhuang ethnicity population ( $\mathrm{TT}$ versus $\mathrm{CC}$ : OR = $0.400,95 \% \mathrm{CI}=0.208-0.770, P=0.006$; $\mathrm{TT}$ versus $\mathrm{CT}$ $+\mathrm{CC}: \mathrm{OR}=0.440,95 \% \mathrm{CI}=0.249-0.775, P=0.004)$. In addition, allele $\mathrm{T}$ revealed a decreased $\mathrm{HBV}$-HCC risk compared with allele $\mathrm{C}(\mathrm{OR}=0.675,95 \% \mathrm{CI}=0.47$ $0.968, P=0.033$ ). However, no significant associations were observed within the subgroups analyzed by age, BMI, smoking, or drinking statuses for the two SNPs (data not shown). 
Table 1: Characteristics of the study populations

\begin{tabular}{lccccc}
\hline & Control (N=224) & CHB (N=120) & LC (N=140) & HCC (N=243) & $P$ \\
\hline Gender, \%(N) & & & & & \\
$\quad$ Male & $55.8(125)$ & $76.7(92)$ & $76.4(107)$ & $91.8(223)$ & $<0.001$ \\
$\quad$ Female & $44.2(99)$ & $23.3(28)$ & $23.6(33)$ & $8.2(20)$ & \\
Age (years), Mean \pm SD & $46.7 \pm 7.04$ & $37.0 \pm 12.0$ & $48.4 \pm 11.94$ & $49.4 \pm 11.2$ & $<0.001$ \\
$\quad<50$ & $60.7(136)$ & $84.1(101)$ & $55.0(77)$ & $55.1(134)$ & $<0.001$ \\
$\quad \geq 50$ & $39.3(88)$ & $15.8(19)$ & $45.0(63)$ & $44.9(109)$ & \\
Ethnicity, \%(N) & & & & \\
$\quad$ Han & $42.4(95)$ & $61.7(74)$ & $61.4(86)$ & $56.8(138)$ & 0.002 \\
$\quad$ Zhuang & $51.8(116)$ & $33.3(40)$ & $36.4(51)$ & $40.3(98)$ & \\
$\quad$ Other & $6.0(13)$ & $5.0(6)$ & $2.1(3)$ & $2.9(7)$ & \\
BMI $\left(\mathrm{kg} / \mathrm{m}^{2}\right)$, & $22.4 \pm 3.5$ & $22.1 \pm 3.40$ & $22.9 \pm 3.6$ & $22.1 \pm 3.4$ & 0.058 \\
Mean $\pm \mathrm{SD}$ & $82.6(185)$ & $84.1(101)$ & $74.3(104)$ & $84.8(206)$ & 0.062 \\
$\quad<25 \mathrm{~kg} / \mathrm{m}^{2}, \%(\mathrm{~N})$ & $17.4(39)$ & $15.8(19)$ & $25.7(36)$ & $15.2(37)$ & \\
$\quad \geq 25 \mathrm{~kg} / \mathrm{m}^{2}, \%(\mathrm{~N})$ & & & & \\
Smoking, \%(N) & $32.1(72)$ & $40.8(49)$ & $42.1(59)$ & $35.0(85)$ & 0.143 \\
$\quad$ Yes & $67.9(152)$ & $59.2(71)$ & $57.9(81)$ & $65.0(158)$ & \\
$\quad$ No & & & & \\
Dinking, \%(N) & $28.1(63)$ & $45.0(54)$ & $27.9(39)$ & $34.6(84)$ & 0.007 \\
$\quad$ Yes & $72.9(161)$ & $55.0(66)$ & $72.1(101)$ & $65.4(159)$ & \\
$\quad$ No &
\end{tabular}

CHB, chronic hepatitis B; LC, liver cirrhosis; HCC, hepatocellular carcinoma; SD, standard deviation; Qualitative characteristics: Chi-squared test; Continuous variables: one-way ANOVA test.

Table 2: Association between Visfatin polymorphisms and risk of CHB, LC, HCC

\begin{tabular}{|c|c|c|c|c|c|c|c|c|c|c|}
\hline \multirow{2}{*}{ Model } & \multirow{2}{*}{$\begin{array}{c}\text { Control } \\
\mathbf{N} \%\end{array}$} & \multicolumn{3}{|c|}{ CHB vs. Control } & \multicolumn{3}{|c|}{ LC vs. Control } & \multicolumn{3}{|c|}{ HCC vs. Control } \\
\hline & & N\% & OR(95\%CI)* & $P^{*}$ & $\mathbf{N} \%$ & OR(95\%CI $)^{*}$ & $P$ & $\mathbf{N} \%$ & OR(95\%CI $)^{*}$ & $P$ \\
\hline \multicolumn{11}{|l|}{$-1535 \mathrm{C}>\mathrm{T}$} \\
\hline $\mathrm{CC}$ & $89(39.7)$ & $52(43.3)$ & $1^{\text {ref }}$ & & $63(45.0)$ & $1^{\text {ref }}$ & & $102(42.0)$ & $1^{\text {ref }}$ & \\
\hline CT & $101(45.1)$ & $46(38.3)$ & $\begin{array}{c}0.847 \\
(0.509-1.409)\end{array}$ & 0.522 & $61(43.6)$ & $\begin{array}{c}0.771 \\
(0.511-1.162)\end{array}$ & 0.214 & $115(47.3)$ & $\begin{array}{c}0.864 \\
(0.587-1.272)\end{array}$ & 0.458 \\
\hline TT & $34(15.2)$ & $22(18.3)$ & $\begin{array}{c}0.956 \\
(0.540-1.693)\end{array}$ & 0.878 & $16(11.4)$ & $\begin{array}{c}0.609 \\
(0.373-0.994)\end{array}$ & 0.047 & $26(10.7)$ & $\begin{array}{c}0.493 \\
(0.313-0.778)\end{array}$ & 0.002 \\
\hline $\begin{array}{l}\text { Dominant } \\
\text { model }\end{array}$ & $135(60.3)$ & $68(56.6)$ & $\begin{array}{c}0.872 \\
(0.534-1.422)\end{array}$ & 0.582 & $77(55.0)$ & $\begin{array}{c}0.729 \\
(0.491-1.081)\end{array}$ & 0.116 & $141(58.0)$ & $\begin{array}{c}0.765 \\
(0.527-1.109)\end{array}$ & 0.157 \\
\hline $\begin{array}{l}\text { Recessive } \\
\text { model }\end{array}$ & & & $\begin{array}{c}1.040 \\
(0.642-1.686)\end{array}$ & 0.872 & & $\begin{array}{c}0.665 \\
(0.430-1.028)\end{array}$ & 0.066 & & $\begin{array}{c}0.535 \\
(0.362-0.791)\end{array}$ & 0.002 \\
\hline $\mathrm{C}$ & $279(62.3)$ & $150(62.0)$ & $1^{\text {ref }}$ & & $187(66.8)$ & $1^{\text {ref }}$ & & $319(65.6)$ & $1^{\text {ref }}$ & \\
\hline $\mathrm{T}$ & $169(37.7)$ & $90(38.0)$ & $\begin{array}{c}0.942( \\
0.682-1.303\end{array}$ & 0.720 & $93(33.2)$ & $\begin{array}{c}0.772 \\
(0.590-1.009)\end{array}$ & 0.058 & $167(34.4)$ & $\begin{array}{c}0.734 \\
(0.581-0.950)\end{array}$ & 0.018 \\
\hline \multicolumn{11}{|l|}{$-3187 \mathrm{G}>\mathrm{A}$} \\
\hline $\mathrm{CC}$ & $52(23.2)$ & $23(19.2)$ & $1^{\text {ref }}$ & & $32(22.9)$ & $1^{\text {ref }}$ & & $50(20.6)$ & $1^{\text {ref }}$ & \\
\hline CT & $122(54.5)$ & $72(60.0)$ & $\begin{array}{c}1.685 \\
(0.900-3.152)\end{array}$ & 0.103 & $84(60.0)$ & $\begin{array}{c}1.150 \\
(0.698-1.895)\end{array}$ & 0.583 & $144(59.2)$ & $\begin{array}{c}1.404 \\
(0.880-2.240)\end{array}$ & 0.154 \\
\hline TT & $50(22.3)$ & $25(20.8)$ & $\begin{array}{c}1.318 \\
(0.676-2.571)\end{array}$ & 0.417 & $24(17.1)$ & $\begin{array}{c}0.820 \\
(0.478-1.410)\end{array}$ & 0.474 & $49(20.2)$ & $\begin{array}{c}1.116 \\
(0.678-1.835)\end{array}$ & 0.665 \\
\hline $\begin{array}{l}\text { Dominant } \\
\text { model }\end{array}$ & $172(76.8)$ & $103(85.8)$ & $\begin{array}{c}1.549 \\
(0.843-2.845)\end{array}$ & 0.159 & $108(77.1)$ & $\begin{array}{c}1.062 \\
(0.650-1.734)\end{array}$ & 0.810 & 193(79.4) & $\begin{array}{c}1.330 \\
(0.842-2.099)\end{array}$ & 0.221 \\
\hline $\begin{array}{l}\text { Recessive } \\
\text { model }\end{array}$ & $222(49.6)$ & $134(55.8)$ & $\begin{array}{c}0.916 \\
(0.572-1.467)\end{array}$ & 0.715 & $132(46.8)$ & $\begin{array}{c}0.737 \\
(0.505-1.075)\end{array}$ & 0.113 & & $\begin{array}{c}0.861 \\
(0.611-1.213)\end{array}$ & 0.392 \\
\hline $\mathrm{C}$ & $226(50.4)$ & $118(49.2)$ & $1^{\text {ref }}$ & & $148(52.8)$ & $1^{\text {ref }}$ & & $244(50.2)$ & $1^{\text {ref }}$ & \\
\hline $\mathrm{T}$ & $222(49.6)$ & $122(50.8)$ & $\begin{array}{c}1.137 \\
(0.820-1.575)\end{array}$ & 0.441 & $132(47.2)$ & $\begin{array}{c}0.931 \\
(0.714-1.214)\end{array}$ & 0.598 & $242(49.8)$ & $\begin{array}{c}1.053 \\
(0.823-1.346)\end{array}$ & 0.682 \\
\hline
\end{tabular}

*Adjusted for age, gender, BMI, ethnicity, smoking and drinking; ref, reference 


\section{Haplotype analysis}

The LD between the two SNPs within the three comparisons was very weak in both patient and control groups (all $D^{\prime}<0.2$ and $r^{2}<0.01$ ). The value of the lowest frequency threshold (LFT) for haplotype analysis is 0.03 , and haplotypes with a frequency less than 0.03 were not considered in the analysis. Finally, four haplotypes (CC, CT, TC, and TT) were constructed according to the observed genotypes of the two SNPs. The frequency of the four haplotypes of the two SNPs are shown in Table 4. The frequency of TC and TT haplotypes was lower than that of $\mathrm{CC}$ and $\mathrm{CT}$ both in patients and controls; however, the frequency of CC, CT, TC and TT did not differ significantly between patients and controls $(P>$ 0.05 ). Based on the statistical results, we did not observe significant associations between the four haplotypes and risk of HBV-related liver diseases (all $P>0.05$, Table 4).

\section{Genotype and allele frequencies among different population}

To observe the differences among genotype and allele frequencies of visfatin $-1535 \mathrm{C}>\mathrm{T}$ and $-3187 \mathrm{G}>\mathrm{A}$ for different populations, we compared our results with those in different races according to the Haplotype Map (HapMap) project (http://www. ncbi.nlm.nih. gov/snp/). Because no data from different races was found in HapMap for $-1535 \mathrm{C}>\mathrm{T}$, we compared the genotype and allele frequencies of this SNP with those of previous studies. As shown in Table 5, the genotype and allele frequencies of $-1535 \mathrm{C}>\mathrm{T}$ in this study were significantly different than that of previous studies from China (Jinan province) [24] $(P<0.001)$ and America $[25](P<0.001)$. There were significant differences in the allele frequencies of $-1535 \mathrm{C}>\mathrm{T}$ in this study compared to those of Singapore's population $(P=0.027)$ [26], but
A

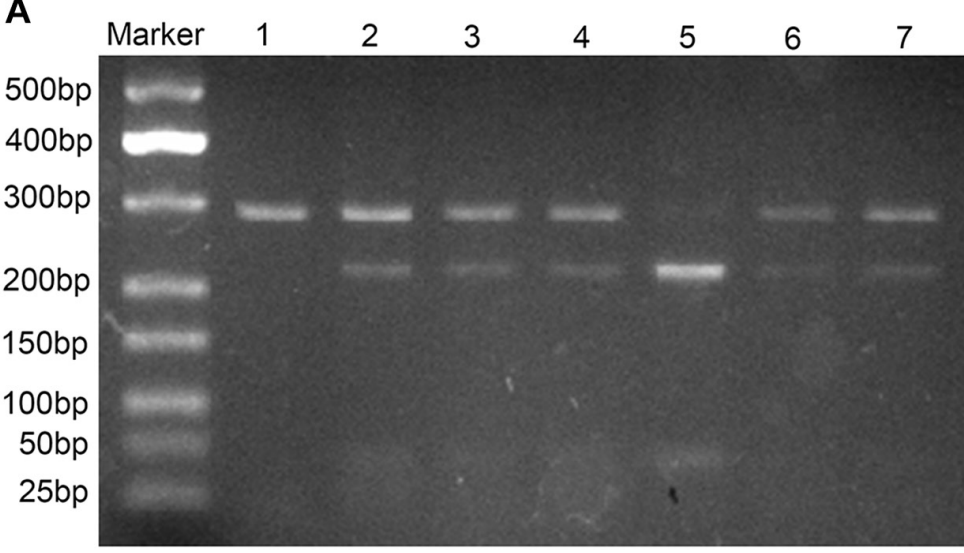

C

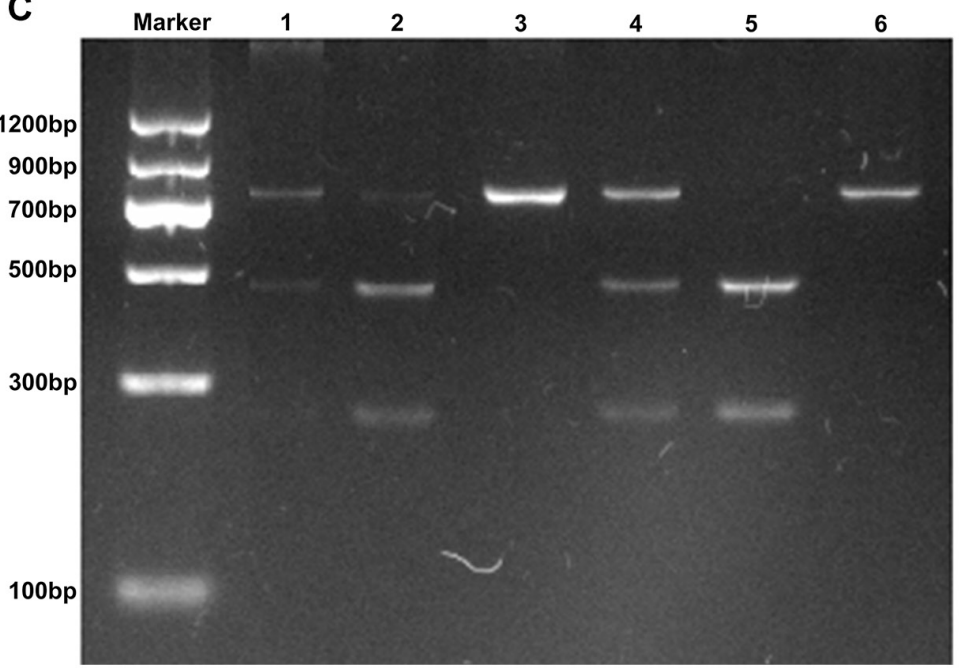

B TT

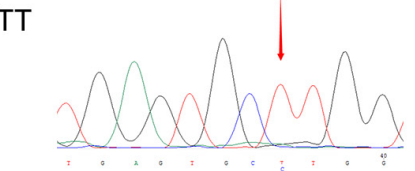

CT

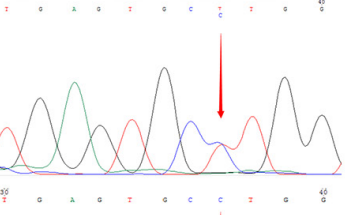

$\mathrm{CC}$

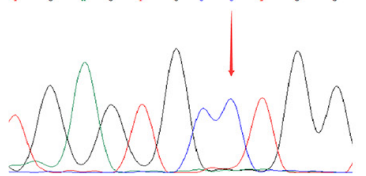

D

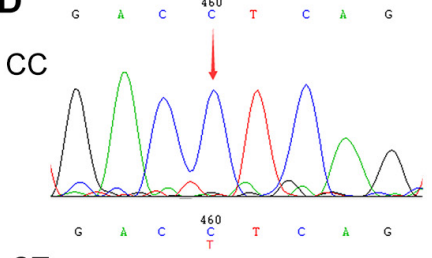

CT
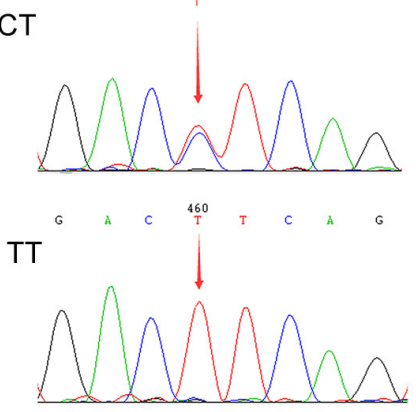

Figure 1: PCR-RFLP and sequencing assay for analyzing the $-1535 C>T$ and $-3187 G>A$ polymorphisms. A. PCR-RFLP assay for $-1535 \mathrm{C}>\mathrm{T}$, lane 1: TT(283bp); lane 2, 3, 4, 6, 7: CT (283bp, $218 \mathrm{bp}, 65 \mathrm{bp})$; lane 5: CC (218bp, $65 \mathrm{bp})$. B. Sequencing assay for $-1535 \mathrm{C}>\mathrm{T}$, the arrays in panels shown TT, CT, and CC, respectively. C. PCR-RFLP assay for $-3187 \mathrm{G}>\mathrm{A}$, lane 1, 2, 4: CT (731bp, 468bp, 263bp); lane 3, 6: CC(731bp); lane 5: TT (468bp, 263bp). D. Sequencing assay for -1535C >T, the arrays in panels shown CC, CT, and TT, respectively. 
Table 3: Stratified effects of Visfatin -1535C $>$ T Polymorphisms on HCC risk estimated by ethnicity

\begin{tabular}{|c|c|c|c|c|}
\hline \multirow{2}{*}{ Ethnicity } & \multirow{2}{*}{ Control, N(\%) } & \multicolumn{3}{|c|}{$\mathrm{HCC}$} \\
\hline & & $\mathbf{N}(\%)$ & OR(95\%CI $)^{*}$ & $P$ \\
\hline Han & $\mathrm{HWE}=0.730$ & & & \\
\hline $\mathrm{CC}$ & $34(35.8)$ & $57(41.3)$ & $1^{\text {ref }}$ & \\
\hline $\mathrm{CT}$ & $47(49.5)$ & $66(47.8)$ & $0.852(0.480-1.511)$ & 0.583 \\
\hline $\mathrm{TT}$ & $14(14.7)$ & $15(10.9)$ & $0.651(0.328-1.289)$ & 0.218 \\
\hline Dominant model & & & $0.804(0.463-1.395)$ & 0.437 \\
\hline Recessive model & & & $0.713(0.397-1.281)$ & 0.257 \\
\hline $\mathrm{C}$ & $115(60.5)$ & $180(65.2)$ & $1^{\text {ref }}$ & \\
\hline $\mathrm{T}$ & $75(39.5)$ & $96(34.8)$ & $0.827(0.577-1.183)$ & 0.298 \\
\hline Zhuang & $\mathrm{HWE}=0.223$ & & & \\
\hline $\mathrm{CC}$ & $49(42.2)$ & $43(43.9)$ & $1^{\text {ref }}$ & \\
\hline CT & $48(41.4)$ & $44(44.9)$ & $0.893(0.513-1.553)$ & 0.688 \\
\hline TT & $19(16.4)$ & $11(11.2)$ & $0.400(0.208-0.770)$ & 0.006 \\
\hline Dominant model & & & $0.729(0.428-1.243)$ & 0.246 \\
\hline Recessive model & & & $0.440(0.249-0.775)$ & 0.004 \\
\hline $\mathrm{C}$ & $146(62.9)$ & $130(66.3)$ & $1^{\text {ref }}$ & \\
\hline $\mathrm{T}$ & $86(37.1)$ & $66(33.7)$ & $0.675(0.471-0.968)$ & 0.033 \\
\hline
\end{tabular}

Table 4: Haplotype analysis between $-1535 \mathrm{C}>\mathrm{T}$ and $-3187 \mathrm{G}>\mathrm{A}$

\begin{tabular}{|c|c|c|c|c|c|c|c|c|c|c|}
\hline \multirow[b]{2}{*}{ Haplotype } & \multicolumn{4}{|c|}{$\mathbf{N}($ frequency) } & \multicolumn{2}{|c|}{ CHB vs Control } & \multicolumn{2}{|c|}{ LC vs Control } & \multicolumn{2}{|c|}{ HCC vs Control } \\
\hline & Control(\%) & СНВ(\%) & $\mathrm{LC}(\%)$ & HCC(\%) & $\boldsymbol{P}$ & OR(95\%CI) & $P$ & OR(95\%CI) & $P$ & OR(95\%CI) \\
\hline $\mathrm{C} \mathrm{C}$ & $144(32.2)$ & $63(26.4)$ & $102(36.4)$ & $161(33.1)$ & 0.113 & $0.76(0.53-1.07)$ & 0.243 & $1.21(0.88-1.65)$ & 0.779 & $1.04(0.79-1.37)$ \\
\hline $\mathrm{C} \mathrm{T}$ & $135(30.1)$ & $87(36.1)$ & $85(30.4)$ & $158(32.6)$ & 0.106 & $1.31(0.94-1.83)$ & 0.931 & $1.01(0.73-1.40)$ & 0.411 & $1.12(0.85-1.48)$ \\
\hline $\mathrm{T} \mathrm{C}$ & $82(18.2)$ & $43(17.8)$ & $46(16.4)$ & $83(17.1)$ & 0.880 & $0.97(0.64-1.46)$ & 0.535 & $0.88(0.59-1.31)$ & 0.659 & $0.93(0.66-1.30)$ \\
\hline $\mathrm{T} \mathrm{T}$ & $87(19.5)$ & $47(19.7)$ & $47(16.8)$ & $84(17.2)$ & 0.939 & $10.2(0.68-1.51)$ & 0.358 & $0.83(0.56-1.23)$ & 0.372 & $0.86(0.62-1.20)$ \\
\hline
\end{tabular}

not in genotype frequencies $(P=0.065)$. Statistically, when compared with this study, the genotype and allele frequencies of $-3187 \mathrm{G}>\mathrm{A}$ were found to be similar with the HCB (Han Chinese in Beijing, Asia) ethnicity and the JPT ethnicity (Japanese in Tokyo, Asia), but significantly different from the CEU ethnicity (Utah residents with Northern and Western European ancestry, Europe) and the YRI ethnicity (Yoruba in Ibadan, Africa). The frequency of TT found in our study $(22.3 \%)$ was significantly higher than those found in the CEU $(8.8 \%)$ and YRI $(0 \%)$ populations, but similar to the HCB $(20.9 \%)$ and the JPT (24.4\%) populations. On the other hand, the occurrence of the $-3187 \mathrm{G}>\mathrm{A}$ CC genotype in this study was $23.2 \%$, which was significantly lower than the levels found in the CEU and YRI populations (55.8\% and 91.2\%, respectively).

\section{DISCUSSION}

Guangxi, a multiracial province in southern China, possesses one of the highest rates of HCC in the world, and the leading cause of $\mathrm{HCC}$ is the high rates of $\mathrm{HBV}$ infection in this region [27]. Over the past decade, studies have demonstrated that genetic variation were related to the risk of HBV-HCC for the Guangxi population [9$11,28,29]$. In this study, we identified that the visfatin $-1535 \mathrm{C}>\mathrm{T}$ polymorphism was associated with HBV-HCC risk. Our data suggested that $\mathrm{HBV}$-infected individuals who carry the visfatin- $1535 \mathrm{C}>\mathrm{T}$ TT genotype may have a lower HCC risk compared with the C-carriers (CC or CT genotypes), especially among those with Zhuang ethnicity.

Our results were consistent with a previous study that examined the association between $-1535 \mathrm{C}>\mathrm{T}$ 
Table 5: Genotype and allele frequencies among different population

\begin{tabular}{|c|c|c|c|c|c|c|c|c|}
\hline \multirow{2}{*}{ SNPs } & \multirow{2}{*}{ Number } & \multicolumn{3}{|c|}{ Genotype Frequency, N(\%) } & \multirow{2}{*}{$P$} & \multicolumn{2}{|c|}{ Allele frequency, $\mathrm{N}(\%)$} & \multirow{2}{*}{$P$} \\
\hline & & TT & $\mathbf{C T}$ & $\mathbf{C C}$ & & $\mathbf{T}$ & $\mathbf{C}$ & \\
\hline \multicolumn{9}{|l|}{$-1535 C>T$} \\
\hline This study & 224 & $34(15.2)$ & $101(45.1)$ & $89(39.7)$ & & $169(37.7)$ & $279(62.3)$ & \\
\hline $\begin{array}{l}\text { China(Jinan) } \\
\text { [31] }\end{array}$ & 405 & $123(30.4)$ & $216(53.3)$ & $66(16.3)$ & $<0.001$ & $462(57.0)$ & $348(43.0)$ & $<0.001$ \\
\hline $\begin{array}{l}\text { American } \\
{[34]}\end{array}$ & 530 & $45(8)$ & $185(35)$ & $300(57)$ & $<0.001$ & $275(26.0)$ & $785(74.0)$ & $<0.001$ \\
\hline $\begin{array}{l}\text { Singapore } \\
{[35]}\end{array}$ & 243 & $47(19.5)$ & $124(51.0)$ & $72(29.5)$ & 0.065 & 218(44.9) & $268(55.1)$ & 0.027 \\
\hline \multicolumn{9}{|l|}{$-3187 G>A$} \\
\hline This study & 224 & $50(22.3)$ & $122(54.5)$ & $52(23.2)$ & & $222(49.6)$ & $226(50.4)$ & \\
\hline $\begin{array}{l}\text { HapMap- } \\
\text { CEU }\end{array}$ & 226 & $20(8.8)$ & $80(35.4)$ & $126(55.8)$ & $<0.001$ & $120(26.5)$ & $332(73.5)$ & $<0.001$ \\
\hline $\begin{array}{l}\text { HapMap- } \\
\text { HCB }\end{array}$ & 86 & $18(20.9)$ & $40(46.5)$ & $28(32.6)$ & 0.233 & $76(44.2)$ & $96(55.9)$ & 0.252 \\
\hline HapMap-JPT & 172 & $42(24.4)$ & $90(52.3)$ & $40(23.2)$ & 0.875 & $174(50.6)$ & $170(49.4)$ & 0.727 \\
\hline $\begin{array}{l}\text { HapMap- } \\
\text { YRI }\end{array}$ & 226 & $0(0)$ & $20(8.8)$ & 206(91.2) & $<0.001$ & $20(4.4)$ & $432(95.6)$ & $<0.001$ \\
\hline
\end{tabular}

polymorphisms and esophageal squamous cell carcinoma (ESCC) risk within a Chinese population [24]. In that study, Zhang et al. found that the TT and CT genotypes of $-1535 \mathrm{C}>\mathrm{T}$ demonstrated significantly decreased ESCC risk when compared with the CC genotype (OR $=0.33, P<0.01 ; \mathrm{OR}=0.47, P<0.01$, respectively), and also showed a decrease when comparing the $\mathrm{T}$ and $\mathrm{C}$ alleles $(\mathrm{OR}=0.48, P<0.01)$ [24]. In another study of 407 bladder cancer patients in southwest China, results indicated that the $-1535 \mathrm{C}>\mathrm{T} \mathrm{C}$ allele significantly increased bladder cancer risk when compared with the $\mathrm{T}$ allele $(\mathrm{OR}=1.24, P=0.047)$. Furthermore, in their study, trends of association within a co-dominant model, dominant model, and recessive model were evident but did not achieve significance; however, there seemed to be a trend toward the incidence of the CC genotype among patients when compared to controls $(25.8 \%$ in patients and $19.9 \%$ in controls) [23]. In addition, subjects with the variant genotypes, CT or TT, also reported reduced risk of CAD, acute respiratory distress syndrome, sepsis, and pneumonia $[20,25,30]$.

The $-1535 \mathrm{C}>\mathrm{T}$ loci is located in the promoter region of the visfatin gene, and the polymorphisms of this SNP, which transition $\mathrm{C}$ to $\mathrm{T}$, might influence the structure or function of the visfatin protein and the visfatin expression in humans. Ye et al. [22] performed a transient luciferase reporter gene assay by transfecting a $\mathrm{C}$ variant or a $\mathrm{T}$ variant pGL3 basic vector into human lung microvascular endothelial cells (HMVECs), and found the $\mathrm{T}$ variant from this SNP resulted in a significant decrease in the transcription rate $(1.8$-fold; $P<0.01)$. Using the same method, Wang et al. also observed the T variant induced nearly a 1.5 fold decrease of promoter activity compared with the $\mathrm{C}$ allele $(P<0.01)$ in human umbilical vein endothelial cells (HUVECs) [31]; as a result, variant genotypes CT and TT correlated with significantly lower levels of serum visfatin compared with genotype CC $[21,32]$. The role of high expression of visfatin in various cancers have been identified by previous studies [33]. In general, overexpression of visfatin increased the activity of a number of signaling pathways that encourage carcinogenesis, such as NAD-dependent SIRTs, PI3K/Akt, ERK1/2, and STAT3 $[33,34]$. The expression of visfatin has been shown to closely interact with inflammation and immune-related cytokines; for example, incubation with IL-6 in HUVECs induced a significant increase in visfatin mRNA levels [31]. With respect to $-1535 \mathrm{C}>\mathrm{T}$, the serum levels of hs-CRP, IL-6, and TNF- $\alpha$ in CC carriers were significantly higher than those of TT carriers [21]. On the basis of previous research, the polymorphism of visfatin $-1535 \mathrm{C}>\mathrm{T}$ being related to HCC risk is biologically plausible.

The difference of the genotype frequency between the ethnic Zhuang and Han populations in this study was not statistically significant $\left(\chi^{2}=1.403, P=0.496\right)$. However, after adjusting for confounding factors, we observed a significant association between visfatin $-1535 \mathrm{C}>\mathrm{T}$ polymorphism and HCC risk among the 
Zhuang population, but not among the Han population. We hypothesized the reason for this difference to be that HCC development may be jointly determined by both genes and the environment. Indeed, most of the ethnic Zhuang population in Guangxi live in rural areas or remote mountainous regions, where the major foods, such as rice, corn, and peanuts, are frequently contaminated by AFB1, which means that people in these regions have more environmental risk factor exposure. Similar conclusions have been reached before. Zeng et al. [35] found APE1148 polymorphisms were associated with increased HCC risk among the Zhuang ethnicity, but not among the Han ethnicity. Long et al. [28] reported that HCC risk was significantly related to both risk genotypes and high-level or long-term AFB1 exposure in the Guangxi population. Therefore, we hypothesized that a gene may not necessarily predict HCC risk by itself, but instead it performed through a complex interaction of genes and the environment. In addition, our research showed a trend toward the CC genotype appearing among HCC patients of Han ethnicity; therefore, a relatively smaller sample size may be another reason for the inconsistent results.

We also observed a statistically significant association between $-1535 \mathrm{C}>\mathrm{T}$ polymorphisms and the risk of HBV-LC, and results indicated that the TT genotype reduced HBV-LC risk by nearly $40 \%$ compared with $\mathrm{CC}$ genotype $(\mathrm{OR}=0.609, P=0.047)$, However, the $P$-value was very close to 0.05 . Moreover, no significant associations between $-1535 \mathrm{C}>\mathrm{T}$ polymorphisms and the risk of $\mathrm{CHB}$ were found in the present study, although the reduced trends of association were evident, as well as the comparison between $\mathrm{CHB}+\mathrm{LC}$ and controls. Due to the relatively smaller sample sizes in the $\mathrm{CHB}$ and $\mathrm{HBV}$ LC groups compared with the HCC group ( $n=120 ; n=$ 140 ; and $n=243$, respectively), the association between $-1535 \mathrm{C}>\mathrm{T}$ polymorphisms and the risk of $\mathrm{CHB}$ and $\mathrm{HBV}$ LC are still uncertain. Therefore, the preliminary results found here must be confirmed by a larger study in the future. Additionally, the associations between visfatin $-3187 \mathrm{G}>\mathrm{A}$ polymorphisms and the risk of CHB, HBV-LC, and $\mathrm{HBV}-\mathrm{HCC}$ were not statistically significant, therefore, the variants of visfatin $-3187 \mathrm{G}>\mathrm{A}$ did not contribute to $\mathrm{HBV}$-related liver diseases in this population.

There were also no significant associations between the four constructed haplotypes, according to the observed genotypes of $-1535 \mathrm{C}>\mathrm{T}$ and $-3187 \mathrm{G}>\mathrm{A}$, and the risk of $\mathrm{CHB}, \mathrm{HBV}-\mathrm{LC}$, and HBV-HCC. Interestingly, Ooi et al. [26] found that $-3187 \mathrm{G}>\mathrm{A}$ and $-1535 \mathrm{C}>\mathrm{T}$ were at complete LD; however, our results showed that the LD between these two SNPs was very weak, which indicated that the contribution of genetic background may be distinct among different populations. Therefore, we further analyzed the genotype and allele frequencies among various populations, and our results confirmed this hypothesis. In fact, although the genotype frequency of $-1535 \mathrm{C}>\mathrm{T}$ loci were consistent with those in the
Singapore population $(P=0.065)$ [26], the difference in the comparison of allele frequency was statistically significant $(P=0.027)$. Additionally, the genotype and allele frequencies of $-1535 \mathrm{C}>\mathrm{T}$ loci in the Guangxi population were significantly different from those in the Jinan, China population [24], and in the US population [25]. With respect to $-3187 \mathrm{G}>\mathrm{A}$, our results were consistent with those of the HCB and the JPT populations, but were significantly different from those of the CEU and YRI populations. These results indicated that the polymorphisms of visfatin vary significantly among ethnicities. In fact, this ethnic variation factor was why we carried out this study in the Guangxi population: Guangxi is a multi-ethnic province in China.

Some limitations should be acknowledged in the present study. First, we studied only two SNPs in the visfatin promoter region, and other SNPs, such as rs2505568, rs9770242, rs1319501, and rs9034, require further study. Second, the study population was limited to the Zhuang and Han ethnicities. Therefore, these findings cannot be generalized to other ethnicities in Guangxi, such as the Yao, Miao, and Dong ethnicities. Third, as mentioned above, a relatively small sample size limited the statistical power in the analysis of this study, therefore, further studies with a larger sample size are required to confirm the results in different regions and races. Nevertheless, our study identified that visfatin$1535 \mathrm{C}>\mathrm{T}$ polymorphisms were associated with reduced HBV-HCC risk, which suggests that this SNP loci may be used as a biomarker to estimate the risk of HCC in the Zhuang population. Our findings pave the way for HCC precision therapy, which is essential for controlling the HCC prevalence in Guangxi.

In summary, our results showed that visfatin $-1535 \mathrm{C}>\mathrm{T}$ polymorphisms were related to a significantly reduced risk of $\mathrm{HBV}-\mathrm{HCC}$, and the genotype TT and the allele $\mathrm{T}$ may be the protective factors for HBV-HCC among the ethnic Zhuang population in Guangxi, China.

\section{MATERIALS AND METHODS}

\section{Subjects}

All participants were recruited at the Third Affiliated Hospital of Guangxi University of Chinese Medicine in Liuzhou, China, during April 2015-January 2016. All participants gave written informed consent for this study, and this study was approved by the Ethics Committee of the Third Affiliated Hospital of Guangxi University of Chinese Medicine.

The study group consisted of $120 \mathrm{CHB}$ patients, $140 \mathrm{HBV}-\mathrm{LC}$ patients, and $243 \mathrm{HBV}-\mathrm{HCC}$ patients. The inclusion of members of the $\mathrm{CHB}$ group were indicated by the following findings: elevated serum alanine aminotransferase (ALT) or aspartate aminotransferase (AST) levels (> $40 \mathrm{IU} / \mathrm{mL})$; or HBV-DNA levels > 1,000 
copies/mL. HBV-LC was diagnosed as described in our previous study [36]. The patient inclusions were primarily based on imaging examinations, through ultrasonography, magnetic resonance imaging, computed tomography, and pathological examination. HBV-HCC was diagnosed according to serum alpha fetal protein (AFP) levels $(>400$ $\mathrm{ng} / \mathrm{mL}$ ) and an imaging examination, while some patients were further confirmed by pathological examination and underwent surgery. The exclusion criteria were patients who were co-infected with hepatitis $\mathrm{A} / \mathrm{C} / \mathrm{D} / \mathrm{E}$ viruses; those who had other liver diseases, such as alcoholic liver diseases, or autoimmune hepatitis; or patients with familial aggregation.

Two hundred and twenty-four control subjects were randomly selected from the medical examination center of the same hospital. All patient controls were asymptomatic HBV carriers: that is, these patients were only hepatitis B surface antigen positive, while all the other laboratory tests, such as AST, ALT, AFP, HBV-DNA copies, and imaging examinations, were negative.

\section{DNA extraction and genotyping}

Genomic DNA was extracted from $2 \mathrm{ml}$ peripheral blood drawn from each subject by the standard phenolchloroform method. The isolated DNA was stored at $-80^{\circ}$ $\mathrm{C}$ until analysis.

Visfatin gene polymorphisms were extracted by polymerase chain reaction (PCR), followed by a PCR-restriction fragment length polymorphism (PCR-RFLP) method. The following primers were used to amplify the PCR products: for $-1535 \mathrm{C}>\mathrm{T}$, 5'TGTTTCAAACCTCGTTGCTGA-3' and reverse 5'AGTGATGGTGGTGGTGGTA-3'; for $-3187 \mathrm{G}>\mathrm{A}$, forward 5'AGCCCAGGATTTTGAGACCA-3' and reverse 5'TCTGTGGATGAGGCCTTTCC-3'. The PCR cycling conditions were $95^{\circ} \mathrm{C}$ for $5 \mathrm{~min}$, followed by 32 cycles at $95^{\circ} \mathrm{C}$ for $30 \mathrm{~s}$, then applying annealing temperatures of $60^{\circ} \mathrm{C}$ for $45 \mathrm{~s}, 72^{\circ} \mathrm{C}$ for $1 \mathrm{~min}$, and a final extension at $72^{\circ} \mathrm{C}$ for $10 \mathrm{~min}$. Then, PCR products were digested overnight at $37^{\circ} \mathrm{C}$ with $\mathrm{MvaI}$ (for $-1535 \mathrm{C}>\mathrm{T}$ ) and AcuI (for $-3187 \mathrm{G}>\mathrm{A}$ ) restriction endonucleases, and further visualized in 3.0\% agarose gel electrophoresis. On the basis of the respective allele size, the genotypes of visfatin-1535C $>\mathrm{T}$ were characterized as TT, CT, and $\mathrm{CC}$, as well as for $-3187 \mathrm{G}>\mathrm{A}$ (Figure 1A, 1C).

To control the quality of genotyping, retesting occurred for any unclear results. Moreover, we randomly selected $10 \%$ of PCR products to validate the results from PCR-RFLP by employing a DNA sequencing analysis using an ABI Prism 3100 (Shanghai Sangon Biotech Co., Ltd., China), and a 100\% concordance rate was achieved (Figure 1B, 1D).

\section{Statistical analysis}

For each SNP, the Hardy-Weinberg equilibrium (HWE) was assessed by Pearson's goodness-of-fit
Chi-square $\left(\chi^{2}\right)$ statistic. The differences of qualitative characteristics, such as the distributions of gender, ethnicity, and genotypic frequencies, were analyzed using the $\chi^{2}$ test. Continuous variables were expressed as the mean \pm standard deviation (SD), and were tested by the one-way ANOVA test. Odds ratios (ORs) with 95\% confidence intervals (CIs) were calculated for each allele in both the patient and control groups, using a binary logistic regressive analysis by adjusting for confounding factors, such as age, gender, smoking, drinking, and ethnicity.

Linkage disequilibrium (LD) analysis and haplotype analysis were performed using SHEsis software (http:// analysis.bio-X.cn) [37]. The value of lowest frequency threshold for haplotype analysis was 0.03 . Lewontin's $D^{\prime}$ and $r^{2}$ were used to evaluate the LD between the two SNPs.

Statistical analysis was performed by SPSS 19.0 software (IBM Corporation, Armonk, NY, USA). All statistical tests were two-tailed, and a $P$-value $<0.05$ was considered statistically significant.

\section{CONFLICTS OF INTEREST}

The authors declare that they have no conflicts of interest.

\section{GRANT SUPPORT}

This study was supported by Liuzhou scientific research and technological development programs (Grant No. 2015J030506); Natural Science Foundation of Guangxi University of Chinese Medicine (Grant No. YB14030) and The Self-funded research project of Guangxi Zhuang Autonomous Region health and Family Planning Commission (Grant No.Z2015206); Youth Science Foundation of Guangxi Medical University (Grant No.GXMUYSF201545); Guigang scientific research and technological development programs (Grant No.1513009).

\section{REFERENCES}

1. Chen W, Zheng R, Baade PD, Zhang S, Zeng H, Bray F, Jemal A, Yu XQ, He J. Cancer statistics in China, 2015. CA Cancer J Clin. 2016.

2. Yang JD, Roberts LR. Hepatocellular carcinoma: a global view. Nature Reviews Gastroenterology \& Hepatology. 2010; 7:448-458.

3. Chuang SC, La Vecchia C, Boffetta P. Liver cancer: descriptive epidemiology and risk factors other than HBV and HCV infection. Cancer letters. 2009; 286:9-14.

4. Mittal S, El-Serag HB. Epidemiology of hepatocellular carcinoma: consider the population. Journal of clinical gastroenterology. 2013; 47:S2-6. 
5. Farazi PA, DePinho RA. Hepatocellular carcinoma pathogenesis: from genes to environment. Nature reviews Cancer. 2006; 6:674-687.

6. Castello G, Scala S, Palmieri G, Curley SA, Izzo F. HCV-related hepatocellular carcinoma: From chronic inflammation to cancer. Clinical Immunology. 2010; 134:237-250.

7. Matsuzaki K, Murata M, Yoshida K, Sekimoto G, Uemura Y, Sakaida N, Kaibori M, Kamiyama Y, Nishizawa M, Fujisawa J, Okazaki K, Seki T. Chronic inflammation associated with hepatitis $\mathrm{C}$ virus infection perturbs hepatic transforming growth factor beta signaling, promoting cirrhosis and hepatocellular carcinoma. Hepatology (Baltimore, Md). 2007; 46:48-57.

8. Teixeira AC, Mendes CT, Jr., Marano LA, Deghaide NH, Secaf M, Elias J, Jr., Muglia V, Donadi EA, Martinelli AL. Alleles and genotypes of polymorphisms of IL-18, TNFalpha and IFN-gamma are associated with a higher risk and severity of hepatocellular carcinoma (HCC) in Brazil. Human immunology. 2013; 74:1024-1029.

9. Deng Y, Li M, Wang J, Xie L, Li T, He Y, Lu Q, Li R, Tan A, Qin X, Li S. Susceptibility to hepatocellular carcinoma in the Chinese population - associations with interleukin-6 receptor polymorphism. Tumour biology: the journal of the International Society for Oncodevelopmental Biology and Medicine. 2014; 35:6383-6388.

10. Lu Y, Wu Z, Peng Q, Ma L, Zhang X, Zhao J, Qin X, Li S. Role of IL-4 gene polymorphisms in HBV-related hepatocellular carcinoma in a Chinese population. PLoS One. 2014; 9:e110061.

11. Xi XE, Liu Y, Lu Y, Huang L, Qin X, Li S. Interleukin17A and interleukin-17F gene polymorphisms and hepatitis $\mathrm{B}$ virus-related hepatocellular carcinoma risk in a Chinese population. Medical oncology (Northwood, London, England). 2015; 32:355.

12. Abenavoli L, Peta V. Role of adipokines and cytokines in non-alcoholic fatty liver disease. Reviews on recent clinical trials. 2014; 9:134-140.

13. Kukla M, Mazur W, Buldak RJ, Zwirska-Korczala K. Potential role of leptin, adiponectin and three novel adipokines - visfatin, chemerin and vaspin-in chronic hepatitis. Molecular medicine (Cambridge, Mass). 2011; 17:1397-1410.

14. Nakajima TE, Yamada Y, Hamano T, Furuta K, Matsuda T, Fujita S, Kato K, Hamaguchi T, Shimada Y. Adipocytokines as new promising markers of colorectal tumors: Adiponectin for colorectal adenoma, and resistin and visfatin for colorectal cancer. Cancer Science. 2010; 101:1286-1291.

15. Gasiorowska A, Talar-Wojnarowska R, Kaczka A, Borkowska A, Czupryniak L, Malecka-Panas E. Serum Leptin, Resistin and Visfatin Concentrations in Patients With Newly Diagnosed Pancreatic Cancer. Gastroenterology. 2013; 144:S659-S659.
16. Nakajima TE, Yamada Y, Hamano T, Furuta K, Gotoda T, Katai H, Kato K, Hamaguchi T, Shimada Y. Adipocytokine levels in gastric cancer patients: resistin and visfatin as biomarkers of gastric cancer. Journal of gastroenterology. 2009; 44:685-690.

17. Ognjanovic S, Bao S, Yamamoto SY, Garibay-Tupas J, Samal B, Bryant-Greenwood GD. Genomic organization of the gene coding for human pre-B-cell colony enhancing factor and expression in human fetal membranes. Journal of molecular endocrinology. 2001; 26:107-117.

18. Zhang YY, Gottardo L, Thompson R, Powers C, Nolan D, Duffy J, Marescotti MC, Avogaro A, Doria A. A visfatin promoter polymorphism is associated with low-grade inflammation and type 2 diabetes. Obesity (Silver Spring, Md). 2006; 14:2119-2126.

19. Bottcher Y, Teupser D, Enigk B, Berndt J, Kloting N, Schon MR, Thiery J, Bluher M, Stumvoll M, Kovacs P. Genetic variation in the visfatin gene (PBEF1) and its relation to glucose metabolism and fat-depot-specific messenger ribonucleic acid expression in humans. The Journal of clinical endocrinology and metabolism. 2006; 91:2725-2731.

20. Yan JJ, Tang NP, Tang JJ, Jia EZ, Wang MW, Wang QM, Zhu J, Yang ZJ, Wang LS, Huang J. Genetic variant in visfatin gene promoter is associated with decreased risk of coronary artery disease in a Chinese population. Clinica chimica acta; international journal of clinical chemistry. 2010; 411:26-30.

21. Wang LS, Yan JJ, Tang NP, Zhu J, Wang YS, Wang QM, Tang JJ, Wang MW, Jia EZ, Yang ZJ, Huang J. A polymorphism in the visfatin gene promoter is related to decreased plasma levels of inflammatory markers in patients with coronary artery disease. Molecular biology reports. 2011; 38:819-825.

22. Ye SQ, Simon BA, Maloney JP, Zambelli-Weiner A, Gao L, Grant A, Easley RB, McVerry BJ, Tuder RM, Standiford T, Brower RG, Barnes KC, Garcia JG. Pre-B-cell colonyenhancing factor as a potential novel biomarker in acute lung injury. American journal of respiratory and critical care medicine. 2005; 171:361-370.

23. Zhang K, Zhou B, Zhang P, Zhang Z, Chen P, Pu Y, Song $\mathrm{Y}$, Zhang L. Genetic variants in NAMPT predict bladder cancer risk and prognosis in individuals from southwest Chinese Han group. Tumour biology: the journal of the International Society for Oncodevelopmental Biology and Medicine. 2014; 35:4031-4040.

24. Zhang C, Yan D, Wang S, Xu C, Du W, Ning T, Liu C, Zhang M, Hou R, Chen Z. Genetic polymorphisms of NAMPT related with susceptibility to esophageal squamous cell carcinoma. BMC Gastroenterol. 2015; 15:49.

25. O'Mahony DS, Glavan BJ, Holden TD, Fong C, Black RA, Rona G, Tejera P, Christiani DC, Wurfel MM. Inflammation and immune-related candidate gene associations with acute lung injury susceptibility and severity: a validation study. PLoS One. 2012; 7:e51104. 
26. Ooi SQ, Chan RM, Poh LK, Loke KY, Heng CK, Chan YH, Gan SU, Lee KO, Lee YS. Visfatin and its genetic variants are associated with obesity-related morbidities and cardiometabolic risk in severely obese children. Pediatr Obes. 2014; 9:81-91.

27. Yeh FS, Yu MC, Mo CC, Luo S, Tong MJ, Henderson BE. HEPATITIS-B VIRUS, AFLATOXINS, AND HEPATOCELLULAR-CARCINOMA IN SOUTHERN GUANGXI, CHINA. Cancer research. 1989; 49:2506-2509.

28. Long XD, Ma Y, Wei YP, Deng ZL. The polymorphisms of GSTM1, GSTT1, HYL1*2, and XRCC1, and aflatoxin B1-related hepatocellular carcinoma in Guangxi population, China. Hepatol Res. 2006; 36:48-55.

29. Peng Q, Li H, Lao X, Deng Y, Chen Z, Qin X, Li S. Association of IL-2 polymorphisms and IL-2 serum levels with susceptibility to HBV-related hepatocellular carcinoma in a Chinese Zhuang population. Infection, genetics and evolution: journal of molecular epidemiology and evolutionary genetics in infectious diseases. 2014; 27:375-381.

30. Liu Y, Shao Y, Yu B, Sun L, Lv F. Association of PBEF gene polymorphisms with acute lung injury, sepsis, and pneumonia in a northeastern Chinese population. Clinical chemistry and laboratory medicine. 2012; 50:1917-1922.

31. Wang YS, Gao W, Li HF, Wang ZM, Zhu J, Zhao H, Yan JJ, Jia EZ, Yang ZJ, Wang LS. Mechanistic insights into the link between visfatin gene $\mathrm{C}-1535 \mathrm{~T}$ polymorphism and coronary artery disease: an in vitro study. Molecular and cellular biochemistry. 2012; 363:315-322.

32. Weng JF, Chen J, Hong WC, Luo LF, Yu W, Luo SD. Plasma visfatin, associated with a genetic polymorphism $-1535 \mathrm{C}>\mathrm{T}$, is correlated with C-reactive protein in Chinese Han patients with traumatic brain injury. Peptides. 2013; 40:8-12.

33. Bi TQ, Che XM. Nampt/PBEF/visfatin and cancer. Cancer Biol Ther. 2010; 10:119-125.

34. Revollo JR, Grimm AA, Imai S. The NAD biosynthesis pathway mediated by nicotinamide phosphoribosyltransferase regulates Sir2 activity in mammalian cells. The Journal of biological chemistry. 2004; 279:50754-50763.

35. Zeng XY, Liu S, Yu HP, Ji L, Li LM, Huang JM, Bai H, Qiu XQ. DNA Repair Capacity, DNA-Strand Break Repair Gene Polymorphisms, and the Incidence of Hepatocellular Carcinoma in Southwestern Guangxi of China. DNA Cell Biol. 2012; 31:1384-1391.

36. Sun Y, Lu Y, Xie L, Deng Y, Li S, Qin X. Interferon gamma polymorphisms and hepatitis B virus-related liver cirrhosis risk in a Chinese population. Cancer cell international. $2015 ; 15: 35$.

37. Li Z, Zhang Z, He Z, Tang W, Li T, Zeng Z, He L, Shi Y. A partition-ligation-combination-subdivision EM algorithm for haplotype inference with multiallelic markers: update of the SHEsis (http://analysis.bio-x.cn/). Cell research. 2009; 19:519-523. 